\title{
Development
}

\section{The impact of opioid and laxative prescribing habits on constipation in the primary care setting before and after the introduction of SIGN 44: Control of pain in patients with cancer}

Pam Lanza and Margaret Carey Department of Clinical Psychology, Stratheden Hospital, Cupar, Fife, UK

\begin{abstract}
The constipating effect of opioids used in cancer pain is widely acknowledged. Opioids account for about a half of constipation in cancer patients, making constipation one of the most prevalent side effects of cancer analgesia. Scottish Intercollegiate Guidelines Network (SIGN) guideline 44 (7.4.1) states explicitly that the appropriate intervention for opioid-induced constipation is a combination of softening and stimulating prophylactic laxatives. Previous literature suggests such practice is not commonplace, implicating a knock-on negative effect to patients' quality of life and highlighting the need for audit in this area. An audit of bowel management in Fife primary care was carried out comparing laxative prescribing practice before and after the publication of SIGN 44: Control of pain in patients with cancer. The data for the audit included all opioid prescriptions including both cancer and non-cancer patients. It was found that publication of SIGN 44 had no significant effect on adherence to the guideline by general practitioners in Fife, at six-, 12- and 18-months post-publication. Implications for quality of life and improving bowel management are discussed.
\end{abstract}

Key words: cancer; constipation; laxatives; opioids; pain; primary care; SIGN 44

Recevied: February 2005; accepted August 2005

Cancer is one of the leading causes of death in the UK. One in three of the population will develop cancer at some stage in their lives and one in four will die of the disease (Potter et al., 2003). Distressing symptoms may occur as a result of the disease process itself, during treatment, or from lack of adequate symptom control. Pain is one of the most frequent and disturbing symptoms of cancer. The World Health Organization's (WHO) classic three-step ladder stipulates that opioids are the

Address for correspondence: Pam Lanza, Department of Clinical Psychology, Stratheden Hospital, Cupar, Fife KY15 5RR, UK. Email: PamLanza@fife-pct.scot.nhs.uk appropriate analgesia for moderate to severe cancer pain (Cherny, 2001). Although opioids are a mainstay of cancer pain management, they are not without adverse side effects.

This audit has addressed the consequences of opioid analgesic use in the treatment of cancer pain. The adverse effects of opioids, opioid-induced constipation, quality of life, cancer care, and quality control in the form of audit procedures and the Scottish Intercollegiate Guidelines Network (SIGN) guidelines are discussed. The prescribing habits of general practitioners (GPs) in Fife pre- and postpublication of SIGN 44: Control of pain in patients with cancer will be investigated and specifically, 
SIGN 44 (7.4.1) which addresses prophylactic co-prescribing of stimulant and softening laxatives with opioids (SIGN, 2001; 2004).

\section{Adverse effects of opioids}

The incidence and severity of side effects from the administration of opioids can play an important role in the success or failure of management in patients with cancer pain. In clinical practice, opioid pharmacotherapy for cancer pain hinges on finding a satisfactory balance between analgesia and side effects. Side effects such as constipation impair quality of life and can be reduced by limiting the dosage of opioid analgesics to patients (McNicol et al., 2003). Until recently, constipation had been understood only in terms of the physical symptoms, regarded as trivial and was not fully recognized as a complex, interactive problem. Treatment has not always been simple. It has been reported that a combination of softening and stimulating laxatives is more likely to maintain normal bowel function at the lowest dose with the least side effects compared to other or no laxatives (Sykes, 1996; Klaschik et al., 2003; McNicol et al., 2003).

\section{Opioid-induced constipation}

Patients do not develop tolerance to opioid-induced constipation and a prophylactic bowel regimen is recommended at initiation of therapy (Bouvy et al., 2002). The constipating effect of opioids is widely acknowledged where opioids account for about $25-50 \%$ of constipation found in terminally ill cancer patients (Fallon and O'Neil, 1997; Sykes, 1998; McQuay, 1999; McMillan and Weitzner, 2000; Foss, 2001; Klaschik et al., 2003; McNicol et al., 2003). It is not just the experience of constipation itself, but also the symptoms that stem from constipation that are problematic for the patient (Pappagallo, 2001; Pearce et al., 2001).

\section{Quality of life}

Constipation is not just an unpleasant physical symptom, but is a consequence of poor pain management that may have a ripple effect, causing much distress and affecting quality of life (McMillan and Small, 2002). Generally, good pain management corresponds with higher quality of life scores compared with poor pain management (Ahmedzai, 1995; Isikhan et al., 2001; Chang et al., 2002; Chochinov et al., 2002; McMillan and Small, 2002; Zaza and Baine, 2002). Additionally, research has indicated that unmanaged side effects such as constipation can increase the chance of hospitalization. It has been reported that constipation was one of four factors that significantly and independently predicted hospice in-patient care (Addington-Hall et al., 1998).

The impact of constipation on quality of life extends beyond the patient themselves. In a review of the literature, Pearce et al. (2001) conclude that direct costs as well as indirect costs are substantial to families and often go unacknowledged. The complexity of the reported costs attached to cancer and cancer care included clinic visits, transport, food, prescriptions, over-the-counter medication, childcare, loss of wages, home care and accessing support.

\section{Cancer care}

Improving cancer and specialist palliative care services has been recognized as central priorities for National Health Services (NHS) Scotland (Scottish Executive, 2001). As GPs in the UK have a central role in cancer treatment and palliative care, it has been suggested that the concept of good cancer pain management should be embedded in a framework of palliative care, taking into consideration, all the different aspects of symptom management (Cherny, 2001). In the UK, it has been reported that $80 \%$ of GPs were prepared to manage cancer pain on their own (Lang et al., 1992; Seamark et al.,1996), despite limited relevant palliative care knowledge (Seamark et al., 1996). Similarly in the US, knowledge and implementation of accepted palliative care practices is haphazard, both with GPs and in hospice care (Barclay et al., 2002). Knowledge and practice of health professionals outside the UK and the US in the care of patients with cancer is also lacking (Von Roenn et al., 1993; Nissen et al., 2001; Bouvy et al., 2002). Worldwide, there seems to be a distinct lack of knowledge and practice in the pain management of patients with cancer.

\section{Quality control}

The SIGN was formed in 1993 'to improve the quality of health care for patients in Scotland by 
reducing variation in practice and outcome, through the development and dissemination of national clinical guidelines containing recommendations for effective practice based on current evidence' (SIGN, 2001: 1). SIGN 44: Control of pain in patients with cancer was published to improve the quality of life for cancer patients. Specifically, Paragraph 7.4.1 states categorically 'Patients receiving an opioid must have access to regular prophylactic laxatives. A combination of stimulant and softening laxative will be required.' (SIGN 44, Evidence Level III, 2000). Local and national audit projects provide invaluable assistance in the implementation of guidelines and indeed, SIGN actively works to encourage and facilitate audit by providing a 'gold standard' against which clinical practice can be judged.

An initial feasibility study investigating the ability to audit the effect of the implementation of SIGN 44 (7.4.1) in the primary care setting in Fife using General Practice Administrative Service Scotland (GPASS) computer databases failed to result in an adequate audit. Limitations included an incomplete data set, an inability to obtain time frames for prescriptions, poor recording habits and small GP participation numbers. However, the results indicated further investigation was warranted and so more accurate data was required. The Common Services Agency (CSA) statistics division are sent all individual prescriptions dispensed in Fife by community pharmacies. They are then processed and stored electronically. The data supplied by the CSA was considered sufficient for this audit.

\section{Aim}

This investigation aimed to compare current practice in Fife against the standard laid out in SIGN 44 Paragraph 7.4.1.

The specific objectives were the following:

1. To identify prevalence of opioid prescriptions with prophylactic laxative prescriptions prepublication of the SIGN guideline and at six-, 12- and 18-months post-publication.

2. To identify prevalence of opioid prescriptions alone.

3. To identify prevalence of all laxative prescriptions (both stimulant and/or softening) prepublication of the SIGN guideline at six-, 12- and 18-months post-publication.
4. Feedback to the specialist palliative care team to improve care and information to patients.
5. Suggest future recommendations and improvements.

\section{Method}

The five Local Healthcare Co-operatives (LHCCs) in Fife (Dunfermline, West Fife, Glenrothes, Kirkcaldy/Levenmouth, North East Fife) were approached and four agreed to participate in the study. Data from the CSA in Edinburgh was accessed and contained prescriptions dispensed in Fife pharmacies from January 2000 to December 2001. This scanned data included prescriptions from all but one of the GP practices in the four LHCCs who agreed to participate. Thus 42 of the 43 GP practices from four LHCCs were involved in the audit. GP practices in the data set from the CSA were not named to maintain confidentiality. The prescription data from CSA also included non-cancer patients with pain. At the time that the CSA data for this project was collected, it was not possible to differentiate cancer and non-cancer patients.

The criteria for inclusion were all opioid prescriptions for pain. The data was then divided into four categories: prescriptions that contained, opioid alone, opioid plus a stimulant laxative, opioid plus a softening laxative, and opioid plus a combination of stimulant and softening laxative. Methadone prescriptions were excluded from the data because the Fife Palliative Care Service reported that methadone is rarely used at the moment as a cancer pain analgesic. Nor was a distinction made between strong and weak opioids as SIGN 44 (7.4.1) makes no distinction between opioid strength.

The data was then divided into four time periods:

- six-months pre-SIGN 44 publication (January-June 2000)

- six-months post-SIGN 44 publication (JulyDecember 2000)

- 12-months post-SIGN 44 publication (JanuaryJune 2001)

- 18-months post-SIGN 44 publication (JulyDecember 2001)

\section{Results}

A summary of all opioid prescriptions is displayed in Table 1. The data from individual GP practices has 
6 Pam Lanza and Margaret Carey

Table 1 Summary of opioid prescriptions across all LHCCs, pre- and post-publication

\begin{tabular}{|c|c|c|c|c|c|}
\hline & \multirow[t]{2}{*}{ Prescriptions } & \multirow{2}{*}{$\begin{array}{l}\text { Pre-SIGN } \\
\text { (January-June 2000) }\end{array}$} & \multicolumn{3}{|c|}{ Post-SIGN } \\
\hline & & & (July-December 2000) & (January-June 2001) & (July-December 2001) \\
\hline$A$ & $\begin{array}{l}\text { Opioid alone } \\
\text { Opioid + stim lax } \\
\text { Opioid + soft lax } \\
\text { Opioid + both }\end{array}$ & $\begin{array}{r}5341 \\
63 \\
0 \\
14\end{array}$ & $\begin{array}{r}4662 \\
59 \\
0 \\
14\end{array}$ & $\begin{array}{r}5039 \\
54 \\
0 \\
21\end{array}$ & $\begin{array}{r}5588 \\
64 \\
0 \\
20\end{array}$ \\
\hline B & $\begin{array}{l}\text { Opioid alone } \\
\text { Opioid + stim lax } \\
\text { Opioid + soft lax } \\
\text { Opioid + both }\end{array}$ & $\begin{array}{r}10301 \\
109 \\
0 \\
77\end{array}$ & $\begin{array}{r}8437 \\
120 \\
0 \\
31\end{array}$ & $\begin{array}{r}8787 \\
157 \\
0 \\
24\end{array}$ & $\begin{array}{r}9580 \\
140 \\
1 \\
21\end{array}$ \\
\hline $\mathrm{C}$ & $\begin{array}{l}\text { Opioid alone } \\
\text { Opioid + stim lax } \\
\text { Opioid + soft lax } \\
\text { Opioid + both }\end{array}$ & $\begin{array}{r}7327 \\
85 \\
0 \\
54\end{array}$ & $\begin{array}{r}7296 \\
76 \\
0 \\
40\end{array}$ & $\begin{array}{r}7189 \\
54 \\
0 \\
55\end{array}$ & $\begin{array}{r}7439 \\
81 \\
0 \\
37\end{array}$ \\
\hline$D$ & $\begin{array}{l}\text { Opioid alone } \\
\text { Opioid + stim lax } \\
\text { Opioid + soft lax } \\
\text { Opioids + both }\end{array}$ & $\begin{array}{r}4490 \\
49 \\
0 \\
33\end{array}$ & $\begin{array}{l}- \\
- \\
- \\
-\end{array}$ & $\begin{array}{r}4584 \\
47 \\
0 \\
19\end{array}$ & $\begin{array}{r}5302 \\
48 \\
0 \\
30\end{array}$ \\
\hline
\end{tabular}

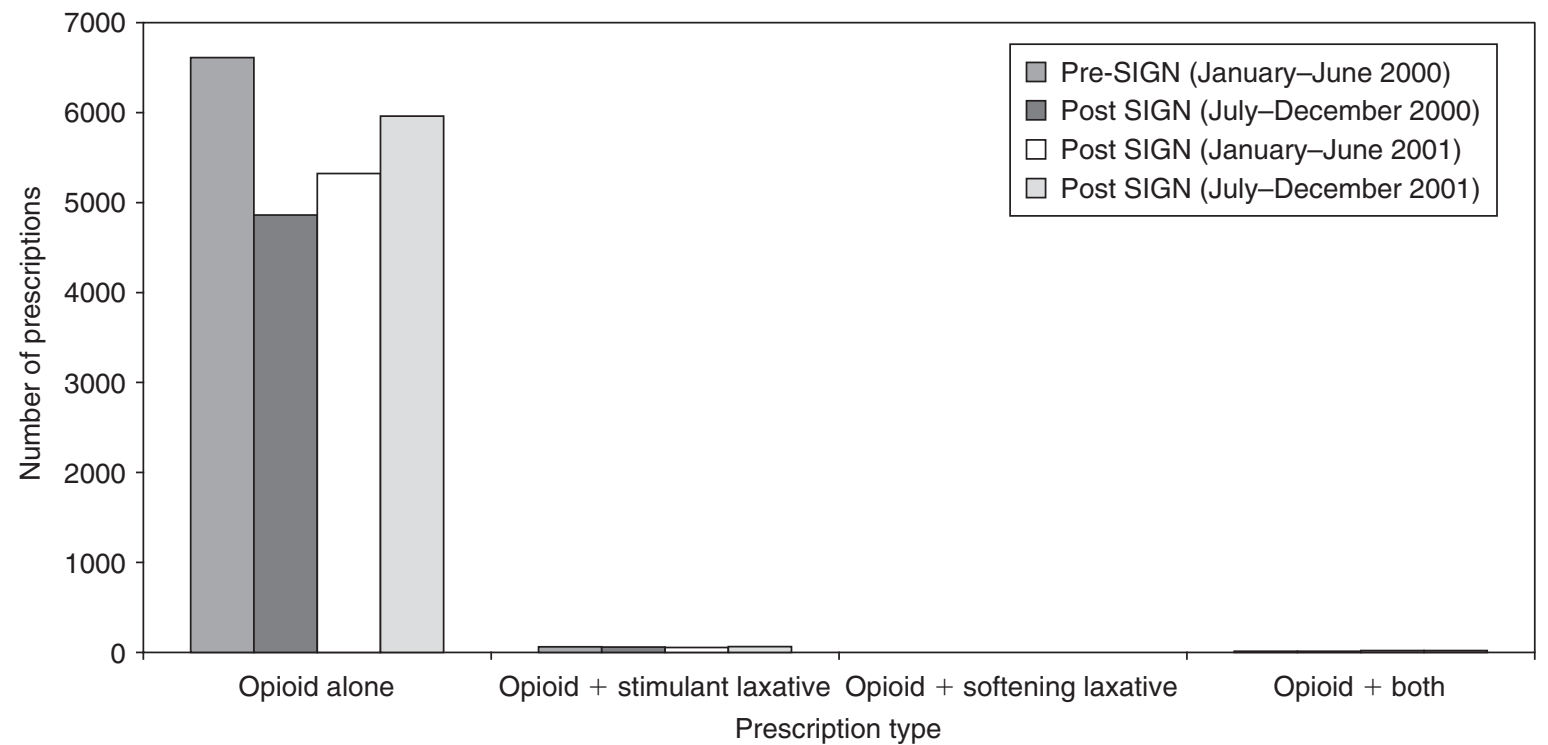

Figure 1 Prescriptions for LHCC A during the audit period

been pooled by LHCC and displayed pre- and postpublication of SIGN 44.

Data was not available for LHCC D for the post-SIGN period, July-December 2000.

It is clear that the publication of SIGN 44 made little difference to the prescribing habits of GPs in the four LHCCs in Fife. The number of prescriptions in all categories varied only marginally across all LHCCs.

As an example, Figure 1 shows the number of prescriptions from one LHCC (LHCC A) during the audit period. 


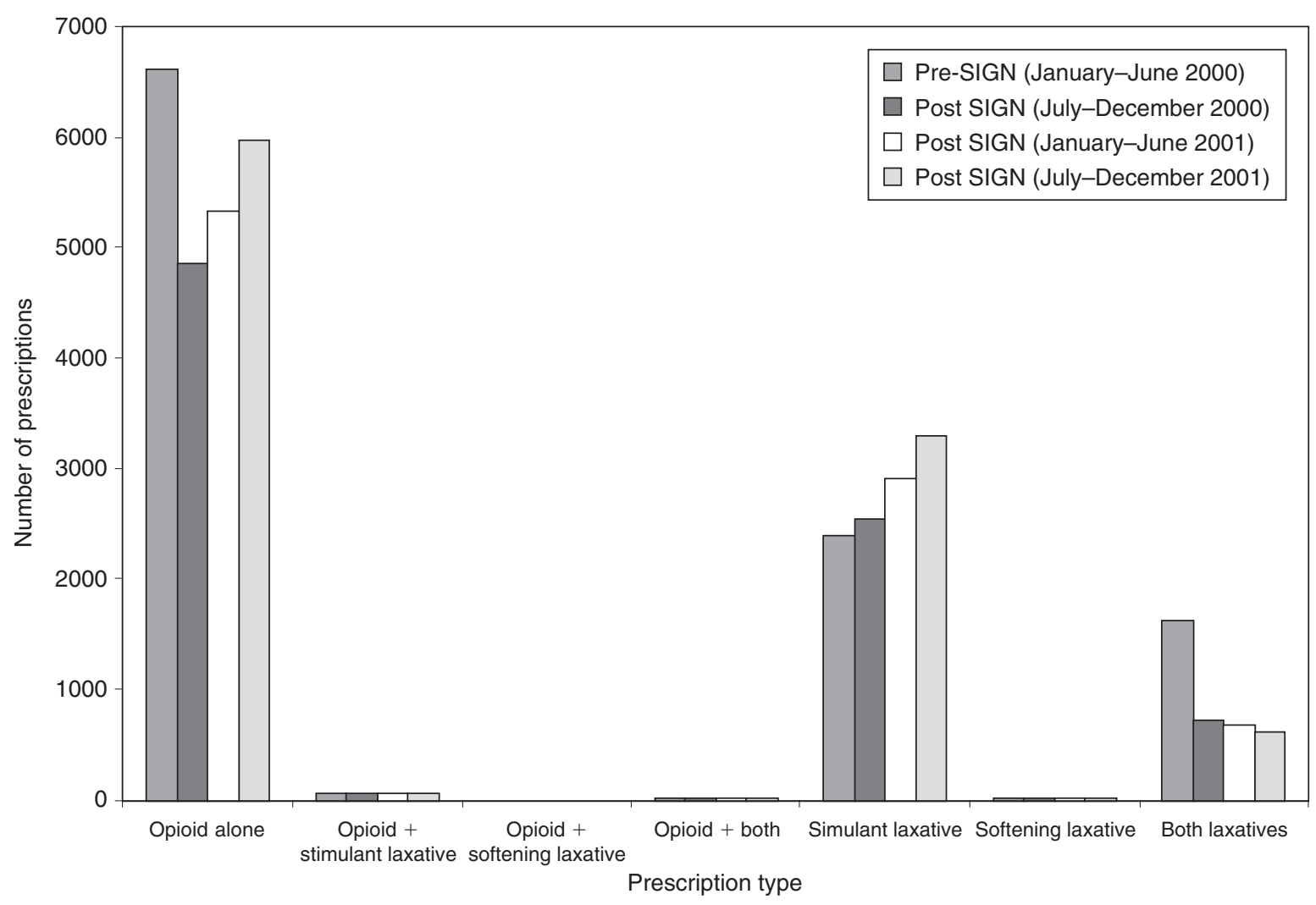

Figure 2 Prescriptions for opioids alone as well as laxatives alone for LHCC A

For the audit period, subsequent data on prescriptions of laxatives alone was also collated. Although SIGN 44 is very explicit, further consideration was given to the number of 'opioid alone' and 'laxative alone' prescriptions.

Figure 2 displays prescriptions of opioids alone as well as laxatives alone for LHCC $\mathrm{A}$ in addition to the combination prescriptions. Although there was an increase in the number of prescriptions, this is no way matched the number of opioid prescriptions.

It would appear that the results of this audit demonstrate that the introduction of SIGN guideline 44 made little difference to an existing lack of prophylactic laxative prescribing by GPs in Fife for patients receiving an opioid for cancer pain. However, the results can only be considered tentatively, because the prescription data used in the audit included both cancer and non-cancer patients.

\section{Limitations}

The data set from the CSA included both initial and subsequent prescriptions of opioid use. It may have been more useful had only 'first prescriptions' been included in the data set. Although SIGN 44 is very explicit in terms of the regular prophylactic co-prescribing of both stimulant and softening laxatives, a possible explanation for the discrepancy between the number of opioid and laxative prescriptions is that the opioid supplied may have been for a shorter time frame than the laxative in the initial prescription, with subsequent prescriptions listing opioids only. The prescription numbers therefore may not be an accurate measure of adherence to the guideline for auditing purposes.

The criteria for prescription inclusion in the audit, "if the script contained an opioid used in cancer pain analgesia or contained an opioid used in cancer pain analgesia along with a softening and/or 
stimulating laxative' was also problematic. The prescription data supplied by the CSA could not differentiate cancer and non-cancer patients. Therefore, our criteria for prescription inclusion could not be satisfied.

\section{Discussion}

Given that the goal of clinical guidelines is the improvement of clinical decision making and the quality of care for patients it would appear that this goal has not been achieved in this audit. There are significant issues concerning the quality of pain management, lack of bowel management and indeed impaired quality of life for cancer patients when constipation is overlooked or mismanaged.

Education of GPs and health professionals needs to be highlighted as an area to be addressed if clinical effectiveness is to improve (Seamark et al., 1996). More research is needed which specifically addresses quality of life with cancer pain patients. Little of the current research on quality of life looks solely at cancer pain and the impact that has on quality of life (McNicol et al., 2003). Very few studies have been conducted that have focused on a physical symptom such as constipation and investigated the impact it has on quality of life as an independent factor. However, constipation seems to be implicated as a predictor of poor quality of life and a factor leading to symptom distress. Clearer links between constipation and quality of life need to be established. Given the vast literature on quality of life and indeed the prevalence and severity of constipation in cancer patients, there is a significant motive to investigate this further.

Moreover, it would not be enough to simply investigate the relationship between constipation and quality of life. Action must be initiated. If best practice is the aim of patient care then adhering to guidelines and clinical governance standards is essential. Possible barriers to adherence to published guidelines need to be investigated further. Are practitioners too busy? Is there peer and/or patient resistance? Is there insufficient access to patient data? Are there administrative obstacles or financial problems? Is there insufficient information and education available? Do practitioners simply forget? These questions remain unanswered, but are important considerations if improved patient care is to be achieved. The process of audit itself will need to continue to be developed and implemented.

\section{Conclusion}

The question of whether the introduction of SIGN 44 improved practice in bowel management has most unequivocally been answered. The practice of prescribing a prophylactic combination of softening and stimulating laxative in concurrence with an opioid has not been shown to improve post-publication of SIGN 44. Possible future action points in the direction of better GP education, improved prescribing habits and practices, better documentation of prescriptions, awareness of constipation, and further research into constipation and quality of life.

Furthermore, the results highlight the importance of audit in evaluating what is going on in current practice. Unfortunately, there is a lack of previous research on the actual prescribing practice of laxatives in recent years in Britain. This study has attempted to address this. Despite the considerable limitations, the results suggest that in Fife, the introduction of SIGN 44 has made little difference to existing prescribing habits in the primary care setting.

\section{Acknowledgements}

The Study was supported by Scottish Cancer Plan Implementation Funding. The authors would like to acknowledge the contribution of Laura Fortune for her initial work on this project.

\section{References}

Addington-Hall, J., Altmann, D. and McCarthy, M. 1998: Which terminally ill cancer patients receive hospice inpatient care? Social Science and Medicine 46, 1011-16.

Ahmedzai, S. 1995: Recent clinical trials of pain control: impact on quality of life. European Journal of Cancer 31A, S2-S7.

Barclay, S., Todd, C., Grande, G. and Lipscombe, J. 2002: Controlling cancer pain in primary care: the prescribing habits and knowledge base of general practitioners. Journal of Pain and Symptom Management 23,383-92.

Bouvy, M.L., Buurma, H. and Egberts, T.C. 2002: Laxative prescribing in relation to opioid use and the influence of pharmacy-based intervention. Journal of Clinical Pharmacy and Therapeutics 27, 107-10.

Chang, V.T., Hwang, S.S. and Kasimis, B. 2002: Longitudinal documentation of cancer pain management outcomes: a pilot study at a VA medical center. Journal of Pain and Symptom Management 24, 494-505.

Cherny, N.I. 2001: The pharmacological management of cancer pain. European Journal of Cancer 37, S265-S278. 
Chochinov, H.M., Hack, T., Hassard, T., Kristjanson, L.J., McClement, S. and Harlos, M. 2002: Dignity in the terminally ill: a cross sectional, cohort study. The Lancet 360 , 2026-30.

Fallon, M. and O'Neil, B. 1997: ABC of palliative care: constipation and diarrhoea. British Medical Journal 315, 1293-6.

Foss, J.F. 2001: A review of the potential role of methylnaltrexone in opioid bowel dysfunction. The American Journal of Surgery 182, S19-S26.

Isikhan, V., Güner, P., Kömürcü, S., Özet, A., Arpaci, F. and Öztïrk, B. 2001: The relationship between disease features and quality of life in patients with cancer. Cancer Nursing 24, 490-95.

Klaschik, E., Nauck, F. and Ostgathe, C. 2003: Constipation modern laxative therapy. Supportive Care in Cancer 11, $679-85$.

Lang, C.C., Beardon, P.H.G., Ladlow, M. and Macrae, W. 1992: Drug management of pain caused by cancer: a study of general practitioners' treatment attitudes and practices. Palliative Medicine 6, 246-52.

McMillan, S.C. and Small, B.J. 2002: Symptom distress and quality of life in patients with cancer newly admitted to hospice home care. Oncology Nursing Forum 29, 1421-28.

McMillan, S.C. and Weitzner, M. 2000: How problematic are various aspects of quality of life in patients with cancer at the end of life? Oncology Nursing Forum 27, 817-23.

McNicol, E., Horowicz-Mehler, N., Fisk, R.A., Bennett, K., Gialeli-Goudas, M., Chew, P.W., Lau, J. and Carr, D. 2003: Management of opioid side effects in cancer-related and chronic noncancer pain: a systematic review. Journal of Pain 4, 231-56.

McQuay, H. 1999: Opioids in pain management. The Lancet 353, 2229-32.

Nissen, L.M., Tett, S.E., Cramond, T., Williams, B. and Smith, M.T. 2001: Opioid analgesic prescribing and use - an audit of analgesic prescribing by general practitioners and the multidisciplinary pain centre at Royal Brisbane Hospital. British Journal of Clinical Pharmacology 52, 693-98.

Pappagallo, M. 2001: Incidence, prevalence, and management of opioid bowel dysfunction. The American Journal of Surgery 182, S11-S18.

Pearce, S., Kelly, D. and Stevens, W. 2001: 'More than just money' - widening the understanding of the costs involved in cancer care. Journal of Advanced Nursing 33, 371-79.

Potter, J., Hami, F., Bryan, T. and Quigley, C. 2003: Symptoms in 400 patients referred to palliative care services: prevalence and patterns. Palliative Medicine 17,310-14.

Scottish Executive. 2001: Cancer in Scotland: action for change. Edinburgh: Scottish Executive.

Scottish Intercollegiate Guidelines Network. 2001: SIGN 44: Control of pain in patients with cancer. Retrieved 13 October 2005 from, www.sign.ac.uk

Scottish Intercollegiate Guidelines Network. 2004: Introduction to SIGN. Retrieved 13 October 2005 from, www.sign.ac.uk/ about/introduction.html

Seamark, D.A., Lawrence, C. and Gilbert, J. 1996: Characteristics of referrals to an inpatient hospice and a survey of general practitioner perceptions of palliative care. Journal of the Royal Society of Medicine 89, 79-84.

Sykes, N.P. 1996: A volunteer model for the comparison of laxatives in opioid-related constipation. Journal of Pain and Symptom Management 11,363-69.

Sykes, N.P. 1998: The relationship between opioid use and laxative use in terminally ill cancer patients. Palliative Medicine $12,375-82$.

Von Roenn, J.H., Cleeland, C.S., Gonin, R., Hatfield, A.K. and Pandya, K.J. 1993: Physician attitudes and practice in cancer pain management. Annals of Internal Medicine 119, $121-26$.

Zaza, C. and Baine, N. 2002: Cancer pain and psychosocial factors: a critical review of the literature. Journal of Pain and Symptom Management 24, 526-42. 